\title{
Conservação dos resíduos da poda de oliveiras na forma de silagem
}

\author{
Antônio Dias Echeverria ${ }^{1}$, Tainara Bremm ${ }^{1}$, Leonardo Ereno Tadielo ${ }^{1}$, Othon Dalla Colleta \\ Altermann $^{1}$, Deise Dalazen Castagnara ${ }^{1}$
}

\footnotetext{
${ }^{1}$ Universidade Federal do Pampa - UNIPAMPA, Campus Dom Pedrito, Dom Pedrito, Rio grande do Sul, Brasil. E-mail: deisecastagnara@yahoo.com.br, tainarabremm@hotmail.com, leonardotadielo@hotmail.com, othon_altermann@hotmail.com, deisecastagnara@yahoo.com.br
}

Recebido: 27/07/2015; Aceito: 12/11/2015

\section{RESUMO}

Por meio de um delineamento inteiramente casualizado procedeu-se a caracterização nutricional de resíduos da poda de oliveiras mantidos in natura ou conservados na forma de silagens durante 110 e 150 dias. Estudou-se o perfil fermentativo por meio da determinação do conteúdo de matéria seca (MS), pH e nitrogênio amoniacal (N$\mathrm{NH}_{3}$ ). A MS elevou-se de 487 para $535 \mathrm{~g} \mathrm{~kg}^{-1}$ com a ensilagem, enquanto o $\mathrm{pH}$ não foi afetado pela ensilagem $(4,77)$ e o N-NH${ }_{3}$ elevou-se de 5,24 para 6,09\% do nitrogênio total. No perfil microbiológico estudaram-se as populações de fungos filamentosos, Lactobacillus, enterobactérias e Clostridium, que apresentaram aumento com a ensilagem. No perfil bromatológico determinou-se os conteúdos de cinzas, matéria orgânica (MO), proteína bruta (PB), fibra em detergente neutro (FDN), fibra em detergente ácido (FDA), lignina, celulose e hemicelulose. Destes, apenas os conteúdos de cinzas, MO, FDA e celulose foram afetados pelos tratamentos, sem efeitos para PB (81 g $\left.\mathrm{kg}^{-1}\right)$ e FDN $\left(679 \mathrm{~g} \mathrm{~kg}^{-1}\right)$. Resíduos da poda de oliveiras podem ser conservados na forma de silagem por $110 \mathrm{ou}$ 150 dias e possuem perfil bromatológico que sugere a possibilidade de sua utilização em dietas de ruminantes, porém, os limites de inclusão somente poderão ser determinados por meio de novos estudos.

Palavras-chave: Bromatologia, fermentação anaeróbia, microrganismos, Olea europaea L.

\section{Conservation of waste of pruning of olive trees in the form of silage}

\begin{abstract}
A nutritional characterization of waste from fresh pruning olive or preserved in the form of silage for 110 and 150 days was carried out through a completely randomized design. The fermentation profile was studied by determining of the dry matter (DM), $\mathrm{pH}$ value and ammonia concentration $\left(\mathrm{N}-\mathrm{NH}_{3}\right)$. The $\mathrm{DM}$ increased from 487 to $535 \mathrm{~g} \mathrm{~kg}^{-1}$ with silage, while the $\mathrm{pH}$ value was not affected by silage (4.77) and $\mathrm{N}^{-\mathrm{NH}_{3}}$ increased from 5.24 to $6.09 \%$ of the total nitrogen. Filamentous fungi populations, such as Lactobacillus, enterobacteria and Clostridium were studied in the microbiological profile. These populations increased with the silage. The ash content, organic matter (OM), crude protein (CP), neutral detergent fiber (NDF), acid detergent fiber (ADF), lignin, cellulose, and hemicellulose were determined in the chemical profile. Only the ash content, OM, ADF and cellulose were affected by the treatments, without effect to $\mathrm{CP}\left(81 \mathrm{~g} \mathrm{~kg}^{-1}\right)$ and $\mathrm{NDF}\left(679 \mathrm{~g} \mathrm{~kg}^{-1}\right)$. Olive pruning waste can be preserved as silage for 110 or 150 days and have chemical profile that suggests the possibility of their use in ruminant diets, however, the limits of inclusion can only be determined through further studies.
\end{abstract}

Key words: Bromatology, anaerobic fermentation, microorganisms, Olea europaea L. 


\section{Introdução}

A oliveira (Olea europaea L.) é uma espécie frutífera da família botânica Oleaceae, cujo plantio tem sido realizado em todos os continentes nas regiões que apresentam clima subtropical ou temperado (COUTINHO et al., 2009), inclusive no Brasil. Seu cultivo visa a produção de frutos para a obtenção do azeite que é o produto final da cadeia produtiva.

Entretanto, ao longo do processo produtivo, vários subprodutos são gerados, dentre eles o resíduo da poda das oliveiras. Este resíduo é obtido anualmente, por ocasião da poda severa ou branda, cada uma delas realizada bianualmente nos olivais. $\mathrm{Na}$ maioria dos cultivos, esses resíduos são mantidos na superfície do solo, podendo atrapalhar o desenvolvimento das práticas agrícolas quando em excesso ou são retirados e depositados em áreas sem cultivo.

Como possuem algum valor nutricional, a possibilidade de uso destes resíduos na alimentação animal eliminaria os riscos ambientais, além de proporcionar às agroindústrias do setor duas novas fontes de renda. A primeira com o tratamento dos resíduos gerados durante o processo produtivo e a segunda com sua comercialização aos pecuaristas para uso na alimentação animal.

O uso de subprodutos agroindustriais na alimentação animal assume ainda um importante papel social, por viabilizar a substituição de alimentos nobres atualmente utilizados em rações, como o milho e farelo de soja, por alimentos alternativos, contribuindo com a segurança alimentar global.

Devido à sazonalidade de produção deste resíduo são necessários estudos a fim de viabilizar a sua conservação nos períodos de produção visando seu uso ao longo das quatro estações do ano ou em épocas de escassez de alimentação para ruminantes. Dentre as tecnologias disponíveis para a conservação de alimentos para consumo por animais tem-se a ensilagem, que consiste no armazenamento anaeróbico de partículas de alimentos, cuja conservação é obtida por meio da anaerobiose e redução do $\mathrm{pH}$ devido à produção de ácidos orgânicos por microrganismos fermentadores de açúcares solúveis (JOBIM et al., 2007).

No entanto, diversos são os fatores que podem afetar o perfil fermentativo e a conservação de alimentos na forma de silagem tais como a matéria seca, capacidade tampão e pH do material a ser ensilado (McDONALD et al., 1991). Para que os subprodutos sejam utilizados sem comprometer a qualidade da dieta animal devem ser armazenados adequadamente e sua composição química deve ser quantificada (SOUZA et al., 2012).

Nesse contexto, objetivou-se com o presente trabalho determinar o perfil fermentativo, microbiológico e bromatológico dos resíduos da poda de oliveiras conservados na forma de silagem durante 110 e 150 dias.

\section{Material e Métodos}

O presente estudo foi desenvolvido no Laboratório de Nutrição Animal e Forragicultura da Universidade Federal do Pampa - UNIPAMPA - Campus Uruguaiana, Rio Grande do Sul, Brasil em parceria com a TECNOLIVAS ${ }^{\circledR}$ Indústria/Pomares de Caçapava do Sul, Rio Grande do Sul, Brasil.

Para a condução do experimento adotou-se o delineamento inteiramente casualizado, com três tratamentos e seis repetições. Os tratamentos consistiram dos resíduos da poda de oliveiras in natura ou conservados na forma de silagens durante 110 e 150 dias. Foram adotados períodos mais longos de fermentação visando proporcionar ao material tempo suficiente para redução do $\mathrm{pH}$, devido as características do material que se apresentava parcialmente lignificado, e, portanto, com baixo conteúdo de carboidratos fermentáveis.

Os resíduos foram obtidos através de poda central de iluminação, na qual são removidos os ramos verticais e de baixa produtividade e propiciando a circulação de ar no interior da copa e a iluminação de gemas de flor e frutos (COUTINHO et al., 2009). Estes foram colhidos em área de pomar de oliveiras em 15/12/2013 com auxílio de tesoura de poda. O processamento dos resíduos foi realizado com auxílio de forrageira agrícola, obtendo-se a trituração dos resíduos em tamanhos de partícula que variaram de $15-35 \mathrm{~mm}$. O processo foi realizado em galpão coberto, onde, a silagem foi homogeneizada sobre uma lona plástica limpa. Por ocasião da ensilagem o material continha valor de matéria seca de 487,86 $\mathrm{g} \mathrm{kg}^{-1}$, acima do limite inferior recomendado por McDonald et al. (1991), não havendo, portanto, a necessidade de uso de aditivos para elevação da matéria seca. Para obtenção das amostras referentes ao tratamento in natura, após a trituração e homogeneização procedeu-se a amostragem de seis exemplares dos resíduos da poda de oliveira.

$\mathrm{Na}$ ensilagem foram utilizados silos experimentais confeccionados com canos de PVC (policloreto de vinila) com $500 \mathrm{~mm}$ de altura e $100 \mathrm{~mm}$ de diâmetro. Visando a obtenção de uma densidade de ensilagem de $0,75 \mathrm{Mg} \mathrm{m}^{-3}$, em cada silo foi acondicionado $3,0 \mathrm{~kg}$ dos resíduos da poda de oliveiras já triturados. A compactação foi realizada manualmente com auxílio de um compactador confeccionado com madeira e os silos lacrados com tampas dotadas de válvulas do tipo Bunsen para o livre escape dos gases; para assegurar o ambiente anaeróbico as tampas foram vedadas aos silos com auxílio de fita adesiva. Visando a drenagem de uma possível produção de efluentes, no fundo de cada silo 
foi colocado $0,5 \mathrm{~kg}$ de areia seca e estéril. Sobre a areia foi disposto um tecido de algodão também estéril, permitindo a separação entre a areia e os resíduos da poda de oliveiras no interior do silo.

Nas datas pré-determinadas em função dos tempos de fermentação pré-estipulados (110 e 150 dias) os silos foram abertos e descarregados. Durante o processo foram descartadas as porções superior $(50 \mathrm{~mm}) \mathrm{e}$ inferior $(50 \mathrm{~mm})$ de cada silo, com posterior homogeneização do material restante. Após a homogeneização procedeu-se a amostragem referente aos tratamentos 110 e 150 dias de fermentação.

Cada amostra coletada, antes da ensilagem e por ocasião da abertura dos silos correspondeu à aproximadamente $500 \mathrm{~g}$ de material. De cada amostra coletada, um volume aproximado de $300 \mathrm{~g}$ foi embalado em saco de papel para determinação da pré-secagem, enquanto os $100 \mathrm{~g}$ foram embalados em sacos plásticos e congelados para a determinação do $\mathrm{pH}$ e nitrogênio amoniacal $\left(\mathrm{N}-\mathrm{NH}_{3}\right)$ e $100 \mathrm{~g}$ foram destinados à determinação do perfil microbiológico.

A matéria seca foi determinada por meio de secagem em estufa com circulação forçada de ar sob temperatura de $55^{\circ} \mathrm{C}$ por 72 horas. $\mathrm{Na}$ determinação do $\mathrm{pH}$ e do $\mathrm{N}$ $\mathrm{NH}_{3}$ as metodologias adotadas foram as descritas em Silva e Queiroz (2009) e Bolsen et al. (1992) respectivamente.

O perfil microbiológico foi estudado por meio da determinação das populações de fungos filamentosos, Lactobacillus, enterobactérias e Clostridium realizada no Laboratório de Diagnóstico de Doenças Infectocontagiosas Bacterianas e Fúngicas Animais da Unipampa, campus Uruguaiana. Nesta etapa, imediatamente após a coleta das amostras as mesmas foram homogeneizadas e diluídas na proporção de $50 \mathrm{~g}$ para $450 \mathrm{~mL}$ de água estéril obtendo-se a diluição de $10^{1}$. Após a primeira diluição foram elaboradas as diluições de $10^{2}$ até $10^{8}$, utilizando-se sempre água estéril. Após as diluições, as amostras foram inoculadas em meios de cultura seletivos. Para crescimento e contagem de fungos filamentosos foi utilizado o meio Potato Destrose Ágar; para Lactobacillus utilizou-se o meio Lactobacillus MRS Broth; para enterobactérias adotou-se o meio Vaiolet Red Bile Ágar (Oxford), enquanto a população de Clostridium foi determinada utilizando-se o meio Reinforced Clostridial Ágar. Nas determinações, após a inoculação as placas foram mantidas sob temperatura de $35^{\circ} \mathrm{C}$ por 72 horas com posterior contabilização das colônias formadas. Em se tratando da determinação de Clostridium, as placas foram mantidas em anaerobiose. Decorrido ao período de incubação as Unidades Formadoras de Colônias (UFC) foram contadas utilizando-se um contador de colônias Quebec, sendo passíveis de serem contadas as placas que apresentaram entre 30 e 300 UFC por placa de petri, e os resultados foram expressos em $\log _{10}$ UFC $\mathrm{g}^{-1}$ de MS.

O perfil bromatológico dos resíduos da poda de oliveiras triturados (in natura) e após as ensilagens foi determinado no Laboratório de Nutrição Animal e Forragicultura. Após a determinação da matéria seca, as amostras foram trituradas em moinho de facas tipo Willey com câmara e peneira de inox, adotando-se o tamanho de partículas de $1 \mathrm{~mm}$. Nas amostras trituradas foram determinadas a correção da matéria seca a $105^{\circ} \mathrm{C}$ e os conteúdos de proteína bruta (PB), fibra em detergente neutro (FDN), fibra em detergente ácido (FDA), lignina, celulose e hemicelulose (SILVA; QUEIROZ, 2009).

Para a análise estatística os dados foram submetidos à análise de variância pelo teste $\mathrm{F}$ ao nível de $5 \%$ de probabilidade e quando constatada significância as médias foram comparadas pelo teste Tukey ao nível de $5 \%$ de probabilidade.

\section{Resultados e Discussão}

Os tratamentos influenciaram significativamente os teores de matéria seca e $\mathrm{N}-\mathrm{NH}_{3}$, mas não afetaram o $\mathrm{pH}$ dos resíduos e silagens (Tabela 1). A matéria seca foi inferior $\left(487,86 \mathrm{~g} \mathrm{~kg}^{-1}\right)$ no resíduo in natura $\mathrm{e}$ apresentou elevação com o decorrer do período de ensilagem (535,82 $\mathrm{g} \mathrm{kg}^{-1}$ ) (Tabela 01). O aumento no conteúdo de matéria seca pode estar relacionado com a drenagem de água por meio da produção de efluentes, uma vez que a densidade de ensilagem foi elevada $\left(0,750 \mathrm{Mg} \mathrm{m}^{-3}\right)$ e a areia encontrava-se levemente umedecida no momento da abertura dos silos. Em todos os tratamentos o teor de matéria seca foi superior (média 511,29 $\mathrm{g} \mathrm{kg}^{-1}$ ) ao recomendado por Mcdonald et al. (1991), que é de $350 \mathrm{~g} \mathrm{~kg}^{-1}$ para proporcionar fermentação adequada no interior do silo. Quando são ensilados materiais com conteúdo de matéria seca superior ao anteriormente estudado, têm-se grande dificuldade na compactação da silagem e, portanto, na expulsão do oxigênio do interior do silo. Neste estudo esse problema foi contornado com a maior densidade adotada para a ensilagem.

Os valores de $\mathrm{pH}$ dos resíduos da poda de oliveiras e suas silagens foram estatisticamente semelhantes com valor médio de 4,77. Os valores obtidos mesmo após a fermentação das silagens excedem o limite superior $(4,20)$ sugerido por McDonald et al., (1991) como favorável para a adequada conservação de alimentos na forma de silagens. Durante a fermentação na produção de silagens os carboidratos são fermentados pelos microrganismos para a produção de ácidos orgânicos, os quais tem a função de reduzir o $\mathrm{pH}$ no interior dos silos para valores entre 3,50 e 4,20 (MCDONALD et al., 1991). 
Quanto mais rápido esse processo ocorrer, mais eficiente será a conservação dos alimentos ensilados. Neste estudo, apesar dos longos períodos de fermentação, o pH não foi reduzido, sugerindo que os resíduos da poda de oliveiras não apresentam conteúdo de carboidratos fermentáveis adequado para a ensilagem do resíduo de forma isolada.

Nestes casos é recomendado o uso de aditivos alimentares, como o farelo de milho como fonte de carboidratos fermentáveis (NERES et al., 2013). No entanto, para que essa recomendação seja extrapolada em nível de propriedades são necessários estudos detalhados que quantifiquem esses carboidratos fermentáveis em resíduos da poda de oliveiras, bem como estudos que contemplem o perfil fermentativo de resíduos da poda de oliveiras ensilados com aditivos alimentares.

Em se tratando do perfil microbiológico, os tratamentos afetaram o perfil microbiológico das silagens obtidas (Tabela 2). Todas as populações de microrganismos foram superiores nas silagens em relação aos resíduos da poda de oliveiras mantidos in natura, porém, foram semelhantes aos resíduos conservados durante 110 e 150 dias de fermentação anaeróbia.

A povoação da massa a ser ensilada por microrganismos acontece ainda por ocasião da colheita, podendo ser ampliada por meio de cepas ou esporos presentes nos maquinários utilizados para colheita e trituração e presentes também no próprio ambiente do silo.

Esse processo pode incluir uma variada população de microrganismos epifíticos, benéficos ou não, que poderão se desenvolver durante o processo de fermentação condicionado às características do material ensilado e aos cuidados adotados na vedação do silo (MCDONALD et al., 1991).

A população de fungos filamentosos apresentou aumento com a ensilagem assim como as enterobactérias (Tabela 2). Este resultado deve-se à alta matéria seca presente no material ensilado (Tabela 1), a qual dificultou a compactação no interior dos silos e favoreceu o desenvolvimento dos microrganismos espoliadores.

A presença destes microrganismos é extremamente indesejável pelos prejuízos nutricionais e sanitários ocasionados; visto que os mesmos se desenvolvem até que ocorra o consumo de todo o oxigênio no interior dos silos, eles se tornam responsáveis pela produção de ácido acético, elevação do pH e aumentos de temperatura no interior dos silos (MCDONALD et al., 1991).

Tabela 1. Valores de matéria seca, $\mathrm{pH}$ e nitrogênio amoniacal $\left(\mathrm{N}-\mathrm{NH}_{3}\right)$ de resíduos da poda de oliveiras mantidos in natura e conservadas em silagens sob condições anaeróbicas com 110 e 150 dias.

\begin{tabular}{llll}
\hline Tratamentos & Matéria Seca $\left(\mathrm{g} \mathrm{kg}^{-1}\right)$ & $\mathrm{pH}$ & $\mathrm{N}^{-N_{3}}(\% \mathrm{~N} \mathrm{Total})^{-}$ \\
\hline in natura & $487,86 \mathrm{~b}$ & $4,75 \mathrm{a}$ & $5,24 \mathrm{~b}$ \\
110 dias & $510,20 \mathrm{a}$ & $4,81 \mathrm{a}$ & $5,92 \mathrm{a}$ \\
150 dias & $535,82 \mathrm{a}$ & $4,76 \mathrm{a}$ & $6,09 \mathrm{a}$ \\
\hline Significância & 0,000 & 0,818 & 0,006 \\
\hline CV $(\%)$ & 2,64 & 3,53 & 7,08 \\
\hline EPM & 0,605 & 0,069 & 0,166
\end{tabular}

Médias seguidas de letras diferentes minúsculas na coluna diferem estatisticamente pelo teste Tukey (5\%). CV: Coeficiente de variação; EPM: erro padrão da média.

Tabela 2. Perfil microbiológico de resíduos da poda de oliveiras mantidos in natura e suas silagens com 110 e 150 dias de armazenamento sob condições anaeróbicas.

\begin{tabular}{lllll}
\hline Tratamentos & Fungos Filamentosos & Lactobacillus & Enterobactérias & Clostridium \\
\hline in natura & $5,20 \mathrm{~b}$ & $0,71 \mathrm{~b}$ & $3,85 \mathrm{~b}$ & $3,85 \mathrm{~b}$ \\
110 dias & $8,30 \mathrm{a}$ & $8,22 \mathrm{a}$ & $8,30 \mathrm{a}$ & $8,30 \mathrm{a}$ \\
150 dias & $7,54 \mathrm{a}$ & $8,23 \mathrm{a}$ & $7,83 \mathrm{a}$ & $7,66 \mathrm{a}$ \\
\hline Significância & 0,000 & 0,000 & 0,000 & 0,000 \\
\hline CV $(\%)$ & 10,50 & 11,82 & 11,64 & 11,07 \\
\hline EPM & 0,301 & 0,276 & 0,316 & 0,298
\end{tabular}

Médias seguidas de letras diferentes minúsculas na coluna diferem estatisticamente pelo teste Tukey (5\%). CV: Coeficiente de variação; EPM: erro padrão da média. *Dados expressos em $\log _{10} \mathrm{UFC} \mathrm{g}^{-1}$ de matéria seca. 
Os elevados valores de $\mathrm{pH}$ obtidos (Tabela 1) reforçam os efeitos negativos da presença das populações destes microrganismos no interior dos silos estudados.

$\mathrm{O} \mathrm{N}-\mathrm{NH}_{3}$ expresso em porcentagem do $\mathrm{N}$ total foi superior nas silagens em relação aos resíduos da poda de oliveiras mantidos in natura (Tabela 1). $\mathrm{O}$ aumento na proporção de $\mathrm{N}-\mathrm{NH}_{3}$ em relação ao $\mathrm{N}$ total com o decorrer dos períodos fermentativos revela que houve quebra de proteínas no interior dos silos com a liberação de compostos nitrogenados não proteicos.

A quebra de proteínas durante os processos fermentativos é decorrente da ação de bactérias proteolíticas cuja atividade é favorecida em ambientes com pH superior a 4,5 (BARON et al., 1986). Dentre essas bactérias destacam-se as do gênero Clostridium, que ao quebrarem as proteínas da silagem ocasionam a elevação do $\mathrm{pH}$ e principalmente, produção de ácido butírico, um ácido fraco e indicativo de má qualidade da silagem (McDONALD et al., 1991).

As bactérias proteolíticas, ao realizarem a hidrólise de proteínas aumentam o $\mathrm{N}$ não proteico em torno de $70 \%$ do $\mathrm{N}$ total na abertura dos silos (McDONALD et al. 1991), processo que foi observado no presente estudo.

A produção de amônia que ocasionou o aumento do $\mathrm{N}-\mathrm{NH}_{3}$ foi desencadeada indiretamente pelo baixo conteúdo de carboidratos solúveis e fermentáveis presentes nos resíduos da poda de oliveiras ensilados, pois nessas condições, as bactérias ácido láticas utilizam os aminoácidos como fonte de energia para o crescimento microbiano e liberam a amônia livre no interior dos silos (BERNARDES et al., 2005).

A população de Lactobacillus sp., também foi superior nas silagens em relação aos resíduos in natura (Tabela 2). Estas bactérias estão envolvidas no processo homo fermentativo das silagens e são responsáveis por reduzir rapidamente o $\mathrm{pH}$ da silagem no início do processo de fermentação, evitando o desenvolvimento e as fermentações indesejáveis ocasionadas por microrganismos do gênero Clostridium e enterobactérias (McDONALD et al., 1991).

No entanto, no presente estudo, o aumento das populações destes microrganismos não foi suficiente para inibir o desenvolvimento dos demais microorganismos indesejáveis (Tabela 2) devido às características do material ensilado: matéria seca elevada e de baixo conteúdo celular que atuou como fonte de carboidratos solúveis para a ação dos Lactobacillus sp.

Durante a fermentação de silagens é comum o aumento da MS diminuindo as possibilidades de perdas por efluente e o desenvolvimento de bactérias do gênero Clostridium (McDONALD et al., 1991). Entretanto, no presente estudo, mesmo com o aumento da MS (Tabela
1) houve aumento na população de Clostridium nas silagens em relação aos resíduos da poda de oliveiras mantidos in natura. Este aumento foi ocasionado pelo ambiente anaeróbico que favorece o desenvolvimento do Clostridium e pelo valor de $\mathrm{pH}$ que inicialmente favoreceram o desenvolvimento dos microrganismos deste gênero, posteriormente sendo mantidos pela sua atividade fermentativa e contribuindo para valores de $\mathrm{pH}$ superiores aos recomendados por McDonald et al. (1991).

Apesar do poder fermentativo dos microrganismos do gênero Clostridium, estes realizam fermentações secundárias indesejáveis as quais desencadeiam a formação de ácido butírico, que se trata de um ácido fraco, com baixo potencial de redução do $\mathrm{pH}$ no interior dos silos (McDONALD et al., 1991). Por este motivo, elevados valores de $\mathrm{pH}$ e a presença de microrganismos do gênero Clostridium caracterizam silagens de baixa qualidade sanitária e fermentativa.

Em se tratando do perfil bromatológico do material in natura e das silagens obtidas os conteúdos de proteína bruta encontrados sugerem a possibilidade de utilização das silagens na alimentação de ruminantes, pois se encontram acima (média $81,48 \mathrm{~g} \mathrm{~kg}^{-1}$ ) do limite proposto por Van Soest (1994) e adequado ao funcionamento do rúmen, que é de $70 \mathrm{~g} \mathrm{~kg}^{-1}$. Por sua vez, dietas com teores de PB abaixo desse conteúdo limitam o desenvolvimento dos microrganismos do rúmen e o correto funcionamento ruminal.

Os conteúdos de cinzas, MO, FDA e celulose foram alterados (Tabela 3). As cinzas decresceram com o decorrer dos períodos de ensilagem ao passo que a MO se elevou, entretanto, não existem justificativas para tais alterações, uma vez que a redução no conteúdo mineral pode ser ocasionada pela produção de efluentes, fato não observado no presente estudo em função do elevado conteúdo de matéria seca dos resíduos da poda da oliveira no momento da ensilagem (Tabela 1). Portanto, as alterações descritas devem-se à heterogeneidade do material ensilado.

O conteúdo de FDN encontrado foi superior ao proposto por Mertens (1994) como limitante para o consumo de ruminantes, o qual é de 550-600 $\mathrm{g} \mathrm{kg}^{-1}$ na base da matéria seca. Desta forma, as silagens obtidas ou os resíduos da poda de oliveiras mantidos in natura não poderiam ser utilizados como única fonte alimentar mesmo para ruminantes de baixa exigência nutricional.

Em se tratando dos demais constituintes, assim como os teores de FDA que foram inferiores nas silagens aos 110 dias $\left(613,85 \mathrm{~g} \mathrm{~kg}^{-1}\right)$ de fermentação e superior nas silagens com 150 dias $\left(645,95 \mathrm{~g} \mathrm{~kg}^{-1}\right)$ de fermentação, enquanto a FDA presente no material in natura foi semelhante aos das silagens (Tabela 3).

A FDA é composta por lignina e celulose (SILVA; QUEIROZ, 2009), portanto, alterações nesses componentes ocasionaram alterações no conteúdo de 
FDA. Os conteúdos de lignina apresentaram comportamento semelhante aos de FDA, porém, sem significância estatística (Tabela 3). Já a celulose também foi inferior nas silagens com 110 dias de fermentação $\left(342,86 \mathrm{~g} \mathrm{~kg}^{-1}\right)$ e superior no material in natura $\left(385,47 \mathrm{~g} \mathrm{~kg}^{-1}\right)$ (Tabela 3). As alterações nas concentrações de carboidratos estruturais em alimentos conservados estão relacionadas com o consumo dos carboidratos solúveis pelos processos fermentativos, os quais, ao serem utilizados pelos microrganismos para produção de ácidos orgânicos têm sua concentração reduzida na matéria seca, propiciando o aumento dos demais constituintes (CASTAGNARA et al., 2012).

Tabela 3. Perfil bromatológico de resíduos da poda de oliveiras mantidos in natura e suas silagens com 110 e 150 dias de armazenamento em silos sob condições anaeróbicas.

\begin{tabular}{lcccc}
\hline Tratamentos & $\begin{array}{c}\mathrm{PB} \\
\left(\mathrm{g} \mathrm{kg}^{-1}\right)\end{array}$ & $\begin{array}{c}\text { Cinzas } \\
\left(\mathrm{g} \mathrm{kg}^{-1}\right)\end{array}$ & $\begin{array}{c}\text { MO } \\
\left(\mathrm{g} \mathrm{kg}^{-1}\right)\end{array}$ & $\begin{array}{c}\text { FDN } \\
\left(\mathrm{g} \mathrm{kg}^{-1}\right)\end{array}$ \\
\hline in natura & $83,25 \mathrm{a}$ & $45,24 \mathrm{a}$ & $954,76 \mathrm{~b}$ & $683,39 \mathrm{a}$ \\
110 dias & $80,60 \mathrm{a}$ & $43,43 \mathrm{ab}$ & $956,57 \mathrm{ab}$ & $668,78 \mathrm{a}$ \\
150 dias & $80,60 \mathrm{a}$ & $40,18 \mathrm{~b}$ & $959,82 \mathrm{a}$ & $683,85 \mathrm{a}$ \\
\hline Significância & 0,585 & 0,004 & 0,04 & 0,258 \\
\hline CV $(\%)$ & 6,21 & 5,23 & 0,23 & 2,54 \\
\hline EPM & 0,206 & 0,337 & 0,092 & 0,703 \\
\hline Tratamentos & FDA & LIG & CEL \\
$\left(\mathrm{g} \mathrm{kg}^{-1}\right)$ & $\left(\mathrm{g} \mathrm{kg}^{-1}\right)$ & $252,34 \mathrm{a}$ & $385,47 \mathrm{a}$ \\
\hline in natura & $631,14 \mathrm{ab}$ & $52,26 \mathrm{a}$ & $244,08 \mathrm{a}$ & $342,86 \mathrm{~b}$ \\
110 dias & $613,85 \mathrm{~b}$ & $46,26 \mathrm{a}$ & $306,62 \mathrm{a}$ & $368,59 \mathrm{ab}$ \\
\hline 150 dias & $645,95 \mathrm{a}$ & $38,60 \mathrm{a}$ & 0,056 & 0,051 \\
\hline Significância & 0,029 & 0,148 & 16,55 & 1,801 \\
\hline CV $(\%)$ & 2,93 & 24,86 & 1,705 & 1,11 \\
\hline EPM & 0,754 & 1,598 \\
\hline
\end{tabular}

Médias seguidas de letras diferentes minúsculas na coluna diferem estatisticamente pelo teste Tukey (5\%). CV: Coeficiente de variação; EPM: erro padrão da média.

Os valores de FDA encontrados são considerados elevados, e devem-se ao alto conteúdo de lignina presente no material (Tabela 3). A indigestibilidade da lignina, por se tratar de um composto fenólico, tem efeitos negativos sobre a digestibilidade dos demais constituintes da dieta (SILVA; QUEIROZ, 2009). Os compostos fenólicos presentes na lignina são tóxicos aos microrganismos do rúmen afetando a digestibilidade dos carboidratos da dieta (JUNG; ENGELS, 2002); seu excesso pode indisponibilizar a proteína dietética, causando redução no consumo (ROGERIO et al., 2007). Os elevados conteúdos de lignina observados no material in natura e nas silagens devem-se à presença de ramos no material amostrado para o estudo. Para verificação do potencial de utilização desse resíduo são necessários novos estudos contemplando apenas as porções mais tenras dos ramos e submetendo o material a tratamento cujo método solubilize parte da lignina e viabilize o aumento da digestibilidade dos demais constituintes.

Para estabelecimento dos níveis de inclusão dos alimentos estudados em dietas de ruminantes são necessários novos estudos visando confirmar as possibilidades de utilização dos alimentos estudados no presente trabalho.

\section{Conclusões}

A conservação de resíduos da poda de oliveiras propicia a obtenção de silagens com perfil fermentativo e microbiológico inadequados para a utilização na alimentação animal.

O perfil bromatológico obtido para os resíduos da poda de oliveiras mantidos in natura ou ensilados por 110 ou 150 dias sugere a possibilidade de utilização dos mesmos em dietas de ruminantes, porém, os limites de inclusão somente poderão ser determinados por intermédio de novos estudos

\section{Referências Bibliográficas}

BARON, V.S.; STEVENSON, K.R.; AND BUCHANANSMITH, J.G. Proteolysis and fermentation of grain-corn ensiled at several moisture levels and under several simulated storage methods. Canadian Journal Animal Science, Ontario, v. 66, n. 2, p.451-461, 1986.

BERNARDES, T.F.; REIS, R.A.; MOREIRA, A.L. Fermentative and microbiological profile of marandu-grass 
ensiled with citrus pulp pellets. Scientia Agricola, PiracicabaSP, v. 62, n. 3, p. 214-220, 2005.

BOLSEN, K.K.; LIN, C.; BRENT, B. E.; FEVERHERM, A. M.; URBAN, J. E.; AIMUTIS, W. R. Effect of silage additives on the microbial succession and fermentation process of alfalfa and corn silages. Journal of Dairy Science, v.75, n.11, p. 3066-3083, $1992 . \quad$ Acesso em: <http://download.journals.elsevierhealth.com/pdfs/journals/00 22-0302/PIIS0022030292780709.pdf〉.

CASTAGNARA, D. D.; NERES, M.A.; OLIVEIRA, P.S.R.; JOBIM, C.C.; TRÊS, T.T.; MESQUITA, E.E.; ZAMBOM, M.A. Use of a conditioning unit at the haymaking of Tifton 85 overseeded with Avena sativa or Lolium multiflorum. Revista Brasileira de Zootecnia, Viçosa-MG, v. 41, n. 6, p. $1353-$ 1359, 2012.

COUTINHO, E.F.; CARLOTTO, F. CAPPELLARO, T.H. Sistemas de produção: Cultivo de Oliveira (Olea europaea L.). Embrapa Clima Temperado, Pelotas-RS, 2009. 125 p.

JOBIM, C.C.; NUSSIO, L. G.; REIS, R. A.; SCHMIDT, P. Avanços metodológicos na avaliação da qualidade da forragem conservada. Revista Brasileira de Zootecnia, Viçosa-MG, v. 36, supl.Esp., p.101-119, 2007. <http://dx.doi.org/10.1590/S1516-35982007001000013>.

JUNG, H.G.; ENGELS, F.M. Alfalfa stem tissues: cell, wall deposition, composition and degradability. Crop Science, Madison, v. 24, n. 2, p. 524-534, 2002.

McDONALD, P.; HENDERSON, A.R.; HERON, S. The biochemistry of silage. $2^{\text {a }}$ ed: Marloui:Chalcome, 1991, 340 .
MERTENS, D.R. Regulation of forage intake. In: FAHEY JR, G.R. Digestibility in vitro, haymaking. American Society of Agronomy, p.450-493, 1994.

NERES, M. A.; ZAMBOM, M. A.; FERNANDES, T.; CASTAGNARA, D. D.; RODRIGUES, J. F. H.; TAFFAREL, L. E.; JAVORSK, C. R.; POZZA, M. S. S. Microbiological profile and aerobic stability of Tifton 85 bermudagrass silage with different additives. Revista Brasileira de Zootecnia, Viçosa-MG, v. 42, n. 6, p. 381-387, 2013. <http://dx.doi.org/10.1590/S1516-35982013000600001>.

ROGERIO, M.C.P.; BORGES, I.; NEIVA, J.N.M. et al. Valor nutritivo do resíduo da indústria processadora de abacaxi (Ananas comosus L.) em dietas para ovinos. 1. Consumo, digestibilidade aparente e balanços energético e nitrogenado. Arquivos Brasileiros de Medicina Veterinária e Zootecnia, Belo Horizonte-MG, v. 59, n. 3, p. 773-781, 2007.

SILVA, D.J.; QUEIROZ, A.C. Análise de Alimentos: métodos químicos e biológicos. $3^{\mathrm{a}}$ ed. Universidade Federal de Viçosa, 235 p. 2009.

SOUZA, L.C.; ZAMBOM, M.A.; POZZA, M.S.S.; NERES, M.A.; RADIS, A.C.; BORSATTI, L.; CASTAGNARA, D.D.; GOUNDT, S. Development of microorganisms during storage of wet brewery waste under aerobic and anaerobic conditions. Revista Brasileira de Zootecnia, Viçosa-MG, v. 41, n. 1, p. 188-193, Jan., 2012.

VAN SOEST, P.J. Nutritional ecology of the ruminant. Ithaca. Constock Publishing Associates. $476 \mathrm{p}$. 